\title{
A compostagem como instrumento de educação ambiental em escolas do Município
}

\section{de João Monlevade - MG}

\author{
Composting as an environmental education instrument in schools in the Municipality of João \\ Monlevade - MG \\ El compostaje como instrumento de educación ambiental en las escuelas del Municipio de João \\ Monlevade-MG
}

Recebido: 29/07/2021 | Revisado: 07/08/2021 | Aceito: 11/08/2021 | Publicado: 14/08/2021

Karen Dayana de Souza Andrade Fontes
ORCID: https://orcid.org/0000-0002-4478-6565
Universidade do Estado de Minas Gerais, Brasil
E-mail: karen.anndrade@ @mail.com
Anna Carolina Lima de Castro
ORCID: https://orcid.org/0000-0001-5302-1524
Universidade do Estado de Minas Gerais, Brasil
E-mail: annacarolinalimadecastro@ gmail.com
Telma Ellen Drumond Ferreira
ORCID: https://orcid.org/0000-0002-0426-6645
Universidade do Estado de Minas Gerais, Brasil
E-mail: telmaellen@ hotmail.com
Eliana Aparecida Panarelli
ORCID: https://orcid.org/0000-0003-1605-6298
Universidade do Estado de Minas Gerais, Brasil
E-mail: eliana.panarelli @uemg.br

\section{Resumo}

Devido ao aumento populacional e dos impactos ambientais, e ainda da carência de informações que envolvem a destinação e o reaproveitamento correto dos resíduos, principalmente o orgânico doméstico, a Educação Ambiental (EA) surge como instrumento pedagógico na construção de novos valores. Nesse contexto, o projeto "Brincando de compostar e aprendendo a reciclar" alcançou 130 alunos do Ensino Fundamental I, de 3 escolas públicas do município de João Monlevade, tendo como objetivo a conscientização e desenvolvimento de um olhar crítico em relação à interação entre o homem e o meio em que vive, dando ênfase a conceitos e valores sustentáveis. Trata-se de um projeto de EA em que foram abordados os aspectos dos diferentes tipos de resíduos (secos e orgânicos), a destinação sustentável do lixo, a compostagem, a coleta seletiva, e o ponto culminante do projeto foi a construção de composteiras para o direcionamento correto dos resíduos orgânicos do ambiente escolar. O projeto teve boa receptividade, por meio da participação e comprometimento dos alunos e professores. Como resultado, as escolas envolvidas obtiveram boas implicações no que tange à compreensão dos benefícios da compostagem para o meio ambiente, além do adubo de boa qualidade que foi posteriormente utilizado em suas hortas e jardins. Ademais, podese concluir que os objetivos foram alcançados de forma satisfatória, uma vez que se trata de um projeto de baixo custo e com potencialidade de trazer benefícios à saúde, ao meio ambiente e à gestão de resíduos sólidos, além de aproximar os alunos dos cuidados com a natureza.

Palavras-chave: Educação básica; Sustentabilidade; Resíduos orgânicos; Coleta seletiva; Impacto ambiental.

\begin{abstract}
Due to the population increase and environmental impacts, and also the lack of information involving the correct destination and reuse of waste, especially domestic organic waste, Environmental Education (EE) emerges as a pedagogical tool in the construction of new values. In this context, the project "Playing to compost and learning to recycle" reached 130 Elementary School I students from 3 public schools in the municipality of João Monlevade, with the objective of raising awareness and developing a critical view of human interaction, and the environment in which they live, emphasizing sustainable concepts and values. This is an EE project in which aspects of different types of waste (dry and organic), sustainable waste disposal, composting, selective collection was addressed, and the culmination of the project was the construction of composters for the correct disposal of organic waste in the school environment. The project was well received, through the participation and commitment of students and teachers. As a result, the schools involved had good implications in terms of understanding the benefits of composting for the environment, in addition to the good quality fertilizer that was later used in their gardens. Furthermore, it can be concluded that the objectives were satisfactorily achieved, since it is a low-cost project with the potential to bring
\end{abstract}


benefits to health, the environment and solid waste management, in addition to bringing students closer together care for nature.

Keywords: Basic education, Sustainability; Organic waste; Selective collect; Environmental impact.

\begin{abstract}
Resumen
Debido al aumento poblacional e impactos ambientales, y también a la falta de información que involucre el correcto destino y reutilización de los residuos, especialmente los orgánicos domésticos, la Educación Ambiental (EA) emerge como una herramienta pedagógica en la construcción de nuevos valores. En este contexto, el proyecto "Jugando al abono y aprendiendo a reciclar" llegó a 130 alumnos de la Escuela Primaria I de 3 escuelas públicas del municipio de João Monlevade, con el objetivo de sensibilizar y desarrollar una visión crítica de la interacción entre los seres humanos y el entorno en el que viven, enfatizando conceptos y valores sostenibles. Se trata de un proyecto de EA en el que se abordaron aspectos de diferentes tipos de residuos (secos y orgánicos), disposición sustentable de residuos, compostaje, recolección selectiva, y la culminación del proyecto fue la construcción de compostadores para la correcta dirección de los residuos orgánicos del ambiente escolar. Proyecto fue bien recibido, gracias a la participación y compromiso de alumnos y profesores. A consecuencia, las escuelas involucradas tuvieron buenas implicaciones con respecto a la comprensión de los beneficios del compostaje para el medio ambiente, además del fertilizante de buena calidad que luego se utilizó en sus jardines. Además, se puede concluir que los objetivos se lograron satisfactoriamente, ya que se trata de un proyecto de bajo costo con potencial para aportar beneficios a la salud, el medio ambiente y la gestión de residuos sólidos, además de acercar a los estudiantes al cuidado de la naturaleza.
\end{abstract}

Palabras clave: Educación básica; Sustentabilidad; Residuo orgánico; Recogida selectiva; Impacto ambiental.

\title{
1. Introdução
}

A carência de informações sobre a destinação correta dos resíduos gerados nas atividades humanas tem contribuído negativamente para a conservação do equilíbrio do ecossistema. Segundo Boff $(2012$, p. 10) “[...] o pior que podemos fazer é não fazer nada e deixar que as coisas prolonguem seu curso perigoso". Diante dessa problemática, que atitudes devem ser tomadas para que as mudanças urgentes de fato se concretizem?

Percebe-se que a destinação inadequada dos resíduos sólidos é um problema ambiental da estação de tratamento de lixo, e deve-se levar em consideração que seu descarte indevido no meio ambiente pode prejudicar o ecossistema e a saúde humana. Entre as tecnologias que podem ser utilizadas, a compostagem é uma das formas de reaproveitar resíduos orgânicos (Costa, Ximenes, Ximenes \& Beltrame, 2015).

A Política Nacional de Resíduos Sólidos (PNRS, Lei 12.305/2010) visa estimular grandes mudanças na forma como o Brasil gerencia os resíduos sólidos. A PNRS estipula que os resíduos devem ser encaminhados para reciclagem e compostagem (Brasil, 2010b). A implantação da coleta seletiva, juntamente com a reciclagem orgânica, é um método que pode ser utilizado para otimizar os serviços de saneamento, já que os aterros sanitários passaram a ser uma forma legalmente adequada de destinação final de resíduos somente após esgotar todos os processos técnicos possíveis de seu tratamento e reciclagem (Brasil, 2010b). De forma diferenciada, a coleta seletiva consiste na prévia separação dos resíduos segundo a sua constituição ou composição, e posteriormente disponibilizados para a coleta (Ministério do Meio Ambiente, 2020).

Conforme o Ministério de Meio Ambiente [MMA] (2020), a compostagem é um processo biológico que acelera a decomposição do material orgânico, tendo como produto final o composto orgânico. Esse tipo de processo visa transformar resíduos orgânicos sólidos em fertilizantes que resultam na melhoria da fertilidade do solo e no crescimento das plantas, através da suplementação dos nutrientes (Oliveira, Oliveira, Bezerra, Pereira \& Battistelle, 2017; Zhao et al., 2017). Essa é uma forma de recuperar os nutrientes dos resíduos orgânicos e levá-los de volta ao ciclo natural, enriquecendo o solo para agricultura ou jardinagem. Sendo assim, essa tecnologia pode reduzir expressivamente o volume de resíduos a serem destinados ao aterro sanitário. É algo simples de ser trabalhado e que traz um retorno positivo e significante. De acordo com o Plano Nacional de Resíduos Sólidos (MMA, 2012), 51,4\% dos resíduos urbanos coletados no Brasil são constituídos por matéria orgânica, portanto, a compostagem torna-se uma solução viável e sustentável para reciclar uma grande parcela dos resíduos orgânicos produzidos no país. 
O manejo adequado desses resíduos contribui para um boa gestão da grande problemática causada em virtude do crescimento gradual da população e do aumento do nível de consumo: o lixo (Freeman, 2021). Ainda, evita os prejuízos resultantes do desperdício alimentício, além de reduzir os danos na saúde pública, na qualidade de vida, no agravamento da degradação ambiental e na manutenção do equilíbrio social (Conto, Binz, Fabrim \& Prates, 2018; Medrado, 2010). Isso sugere que o aproveitamento dos resíduos sólidos, em especial os orgânicos, está ligado aos três pilares do desenvolvimento sustentável: proteção ambiental, desenvolvimento econômico e justiça social.

A interação do indivíduo com a compostagem possibilita uma maior reflexão sobre os cuidados ambientais, bem como, maior compreensão a respeito da autorresponsabilidade sobre a gestão do seu próprio lixo. Ademais, a interação homem-natureza também tem um papel terapêutico para o tratamento de patologias mentais, como depressão e ansiedade (Pitt, 2014). Nesse sentido, é perceptível notar que a Educação Ambiental aliada à compostagem, além de trazer benefícios para o poder público no gerenciamento dos resíduos, também tem um papel fundamental na qualidade de vida dos educandos, na saúde pública e no equilíbrio ecológico.

Tendo em vista a necessidade de ampliar a conscientização ambiental na rede municipal de ensino de João Monlevade, foi idealizado um trabalho voltado para a construção de composteiras em escolas públicas do município. Segundo Medeiros, Mendonça, Souza e Oliveira (2011), crianças bem-informadas sobre as problemáticas ambientais serão adultos mais preocupados com o meio ambiente e transmissores dos saberes adquiridos na escola, levando o conhecimento para casa, família e vizinhos. A compostagem é uma alternativa de tratamento e também de aproveitamento adequado do tipo de resíduo gerado (Teixeira, Germano, Oliveira \& Furlan Júnior, 2004). O desenvolvimento deste projeto envolveu ações de compostagem e coleta seletiva, inserindo no ambiente escolar a conscientização da necessidade da reciclagem dos resíduos orgânicos.

A fim de concretizar a Educação Ambiental nas séries iniciais das escolas do projeto, o objetivo principal deste trabalho foi levar à consciência das crianças do Ensino Fundamental I os benefícios decorrentes da compostagem. Para que as mudanças comportamentais do antropoceno alcancem a sustentabilidade, é necessário levar a sensibilização às crianças, assim será formada uma nova geração de adultos responsáveis ambientalmente e multiplicadores de práticas sustentáveis.

\section{Metodologia}

Este trabalho, de natureza aplicada, utilizou um enfoque qualitativo, seguindo uma interpretação indutiva acerca da análise do caso estudado (Ludke \& Andre, 2013), e foi desenvolvido, inicialmente, através dos procedimentos didáticos de aulas expositivas, debates, dinâmicas e, a seguir, de uma exposição prática dos resultados alcançados, através da fabricação das composteiras escolares. Segundo Gil (2012), a pesquisa aplicada tem como característica principal o interesse na aplicação, na utilização e nas consequências práticas dos conhecimentos adquiridos.

\section{1 Área de estudo}

O município de João Monlevade, cidade escolhida para a implementação do projeto, está localizado na região do Médio Piracicaba, a cerca de $110 \mathrm{~km}$ a leste da capital mineira (Belo Horizonte). Ocupa uma área de 99.158 km² e a população estimada em 2020 é de 80.416 pessoas (IBGE, 2020). A Figura 1 indica a localização do município onde estão situadas as escolas de realização do trabalho. 
Figura 1: Localização do município de João Monlevade- MG.

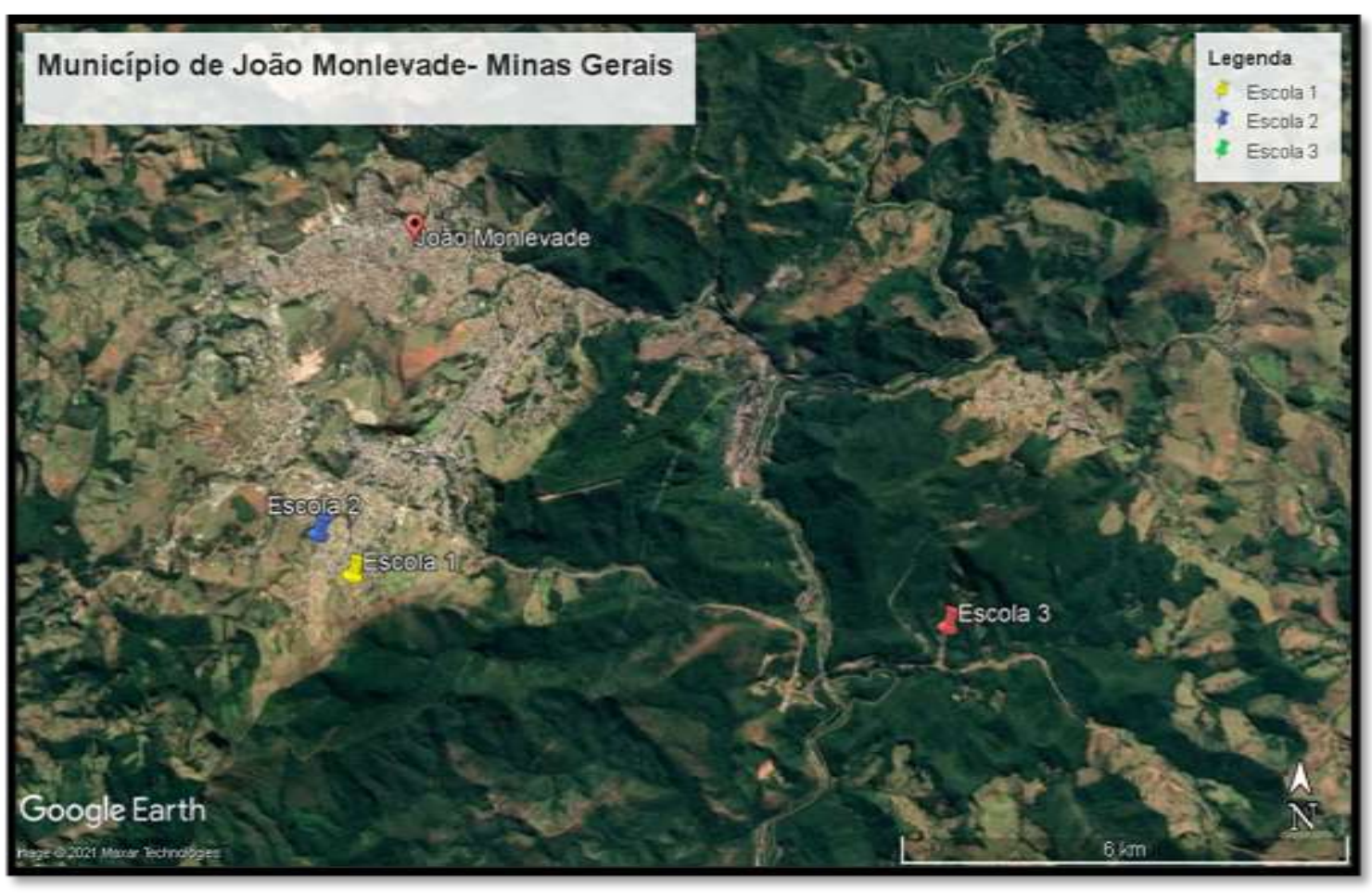

Fonte: Google Earth Pro. Adaptado pelos autores (2021).

\subsection{A Educação Ambiental}

O projeto "Brincando de compostar e aprendendo a reciclar", realizado em 2018, contou com a participação de 130 alunos da faixa etária de 6 a 12 anos e desenvolvido em três escolas do ensino fundamental, localizadas em bairros periféricos da cidade de João Monlevade. O trabalho foi executado em seis etapas, ocorrendo um (1) encontro por semana (totalizando seis semanas) em cada instituição de ensino e com a colaboração dos profissionais da educação de cada escola.

\subsection{Os encontros e a execução do projeto}

A $1^{a}$ visita consistiu em um diagnóstico da escola a fim de verificar a viabilidade da implantação do projeto. Como se trata de um projeto de aplicação simples, os critérios avaliados para sua execução foram: havia uma área para comportar a composteira? O local era plano e seguro? Havia acessibilidade para comportar dezenas de crianças durante a fabricação da composteira? Nesta visita também foi realizada uma conversa com os profissionais responsáveis pela direção da instituição acerca da importância da conscientização ambiental com as crianças.

$\mathrm{O}$ primeiro contato com os alunos ocorreu na $2^{\mathrm{a}}$ semana, onde foram apresentados às crianças alguns conhecimentos básicos a respeito da geração de resíduos e da coleta seletiva. O encontro teve início com algumas perguntas reflexivas a respeito da quantidade de lixo gerado nas escolas e para onde eram destinados esses resíduos, com o intuito de levar à consciência sobre essa problemática ambiental. Em seguida, foi entregue à cada aluno uma imagem impressa de alguns itens típicos de resíduos domiciliares, como embalagens de alimentos de material plástico, papel e vidro, além de imagens de alimentos que representam os restos de comida que são depositados na lixeira, como legumes, frutas, ovos e carne (Figura 2). A partir disso, foi explicada a diferença entre resíduos secos e orgânicos (Figura 3). Posteriormente, foi questionado aos alunos o que as figuras em suas mãos caracterizavam: resíduo seco ou orgânico? Depois da resposta de cada criança, eles foram 
incentivados a transmitir os novos saberes para suas famílias, levando consigo um questionário a ser respondido sobre o tema “Compostagem e Reciclagem”, juntamente com os responsáveis.

Figura 2: Imagens impressas dada às crianças.

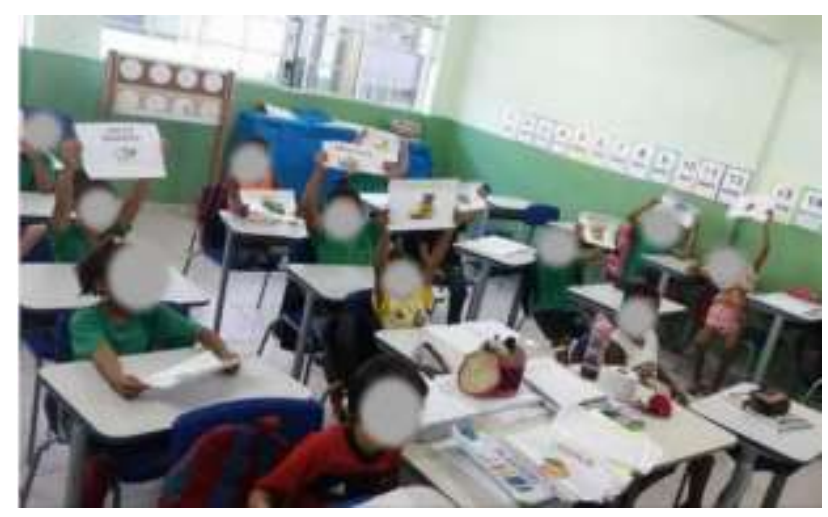

Fonte: Autores (2018).
Figura 3: Abordagem sobre resíduo seco $\mathrm{x}$ resíduo orgânico.

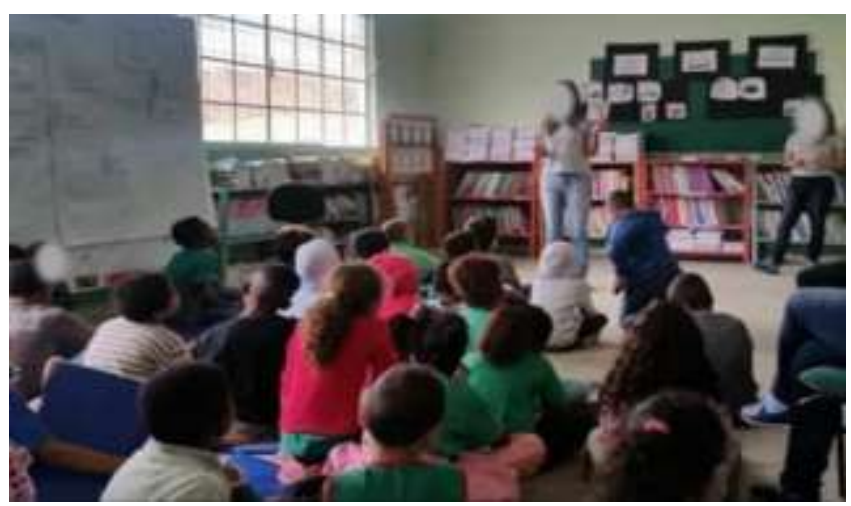

Fonte: Autores (2018).

No $3^{\circ}$ encontro, foi aprofundado o debate acerca dos resíduos orgânicos e como a compostagem contribui para uma destinação mais sustentável desses resíduos. Foram sanadas as dúvidas a respeito do questionário levado para casa na semana anterior. Foi esclarecida a definição e a importância da compostagem, além de reforçar a divulgação da coleta seletiva do município. Foi nessa terceira semana que foi realizado o convite para que todos participassem da fabricação de uma composteira escolar.

$\mathrm{Na} 4^{\mathrm{a}}$ semana, foi ensinado às crianças os tipos de resíduos que são viáveis para irem à composteira, quais devem ser evitados e também foi explicado o porquê e a importância de cada elemento para o bom desempenho do trabalho de decomposição. Por meio de uma dinâmica lúdica, cada criança ganhou um balão de borracha para ser enchido de ar. Dentro de cada balão, havia um papel com o nome de algum resíduo domiciliar (legumes, frutas, vegetais, embalagens plásticas, de papel ou de vidro). Os alunos foram orientados a encherem o balão e brincarem pela sala (Figura 4). Posteriormente, cada criança pegou um balão, estourou, leu o conteúdo do papel e indicou para onde aquele resíduo deveria ser destinado: coleta seletiva ou composteira? Em caso de resíduo seco, o aluno depositou o papel na mini lixeira identificada como "coleta seletiva", caso contrário, em se tratando de lixo orgânico, o aluno depositou em uma garrafa PET que simulava uma "mini composteira". Nesse encontro também foi pedido às crianças para que trouxessem de casa, na semana seguinte, alguns resíduos adequados para esse tipo de reciclagem. 
Figura 4: Dinâmica dos balões.

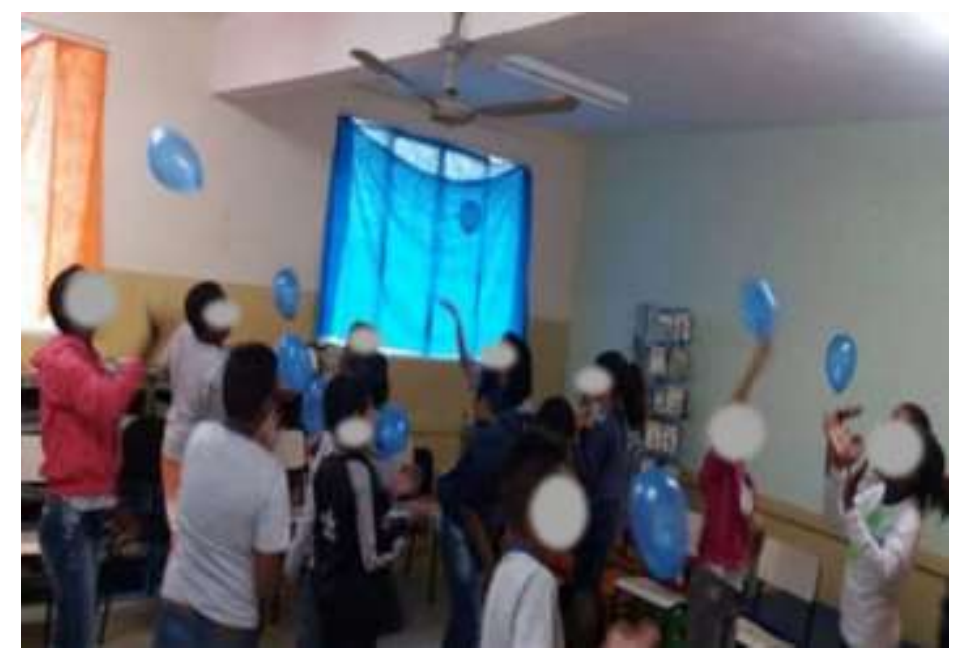

Fonte: Autores (2018).

O penúltimo encontro foi o momento da confecção da composteira. Os materiais utilizados nessa etapa foram duas bombonas recicladas e uma torneira que foi inserida na parte inferior do recipiente. Para o preenchimento da composteira foram utilizados: cascas de frutas, talos de verduras, folhas secas e terra. De posse do material necessário, ocorreu a montagem da composteira, com camadas alternadas de folhas, terra e o resíduo orgânico, até a sua finalização, conforme ilustrado pelas Figuras 5 e 6 .

O último encontro foi idealizado para a averiguação do que foi assimilado e compreendido pelas crianças. Diante disso, foi solicitado aos alunos transmitir para o papel um pouco dos ensinamentos praticados na escola e, para isso, foi pedido para que fizessem uma produção de texto abordando o tema "compostagem" ou um desenho criativo sobre o aprendizado adquirido (Figura 7).

Figura 5: A composteira.

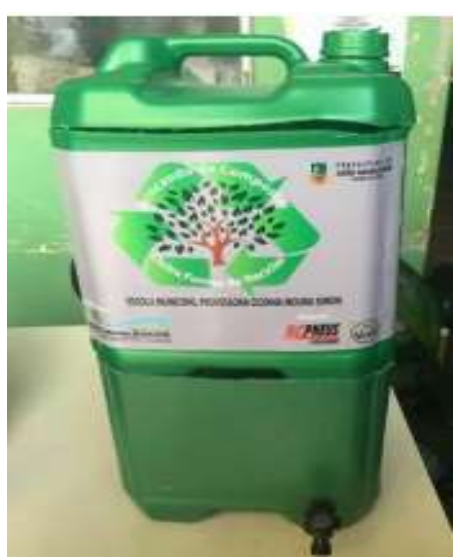

Fonte: Autores (2018)
Figura 6: A fabricação da composteira.

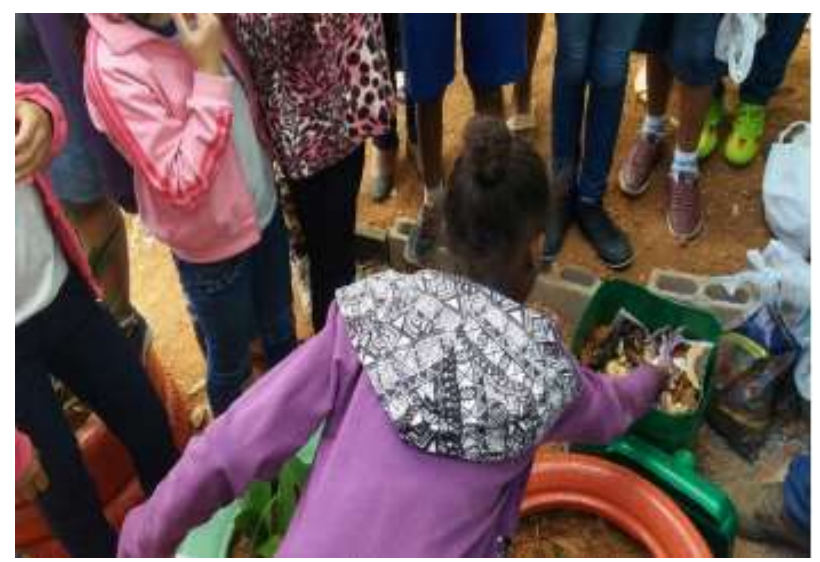

Fonte: Autores (2018). 
Figura 7: Desenho elaborado por uma aluna do $5^{\circ}$ ano.

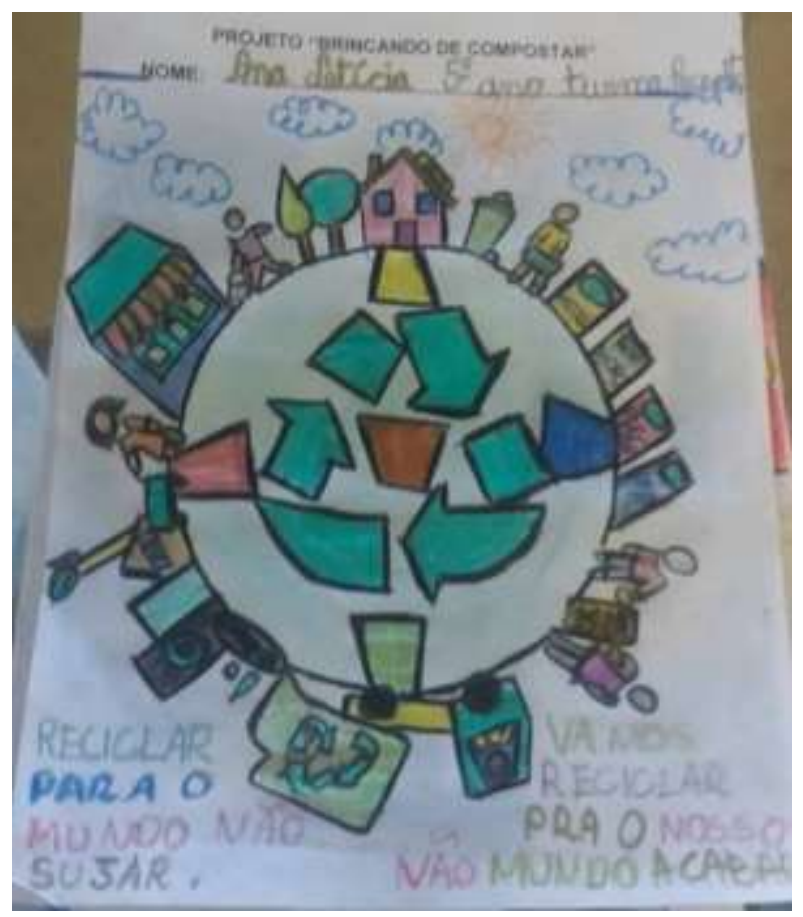

Fonte: Autores (2018).

\section{Resultados}

O desenvolvimento do projeto foi iniciado através de uma conversa informal com os alunos sobre resíduos, em que questionamentos foram levantados a respeito da quantidade da geração de resíduos, do descarte e da reutilização. Foi possível observar que a maioria das crianças desconhecia termos como coleta seletiva, compostagem e impactos ambientais, o que indica a precariedade dos conhecimentos ambientais básicos, comprovando que a falta de informação é o principal desafio para a adoção de práticas sustentáveis.

Foram utilizadas figuras impressas com imagens de diferentes resíduos (secos e orgânicos), para clarificar a compreensão dos alunos acerca dos resíduos domiciliares mais comuns, e também fixar o conteúdo, a fim de que as crianças utilizassem da memória para caracterizar o pensamento. A partir disso, conceituar e explicar as diferenças entre os tipos de lixo, proporcionou uma maior interação e conexão das crianças à temática, permitindo maior entendimento sobre a classificação e a tipologia dos resíduos.

Diante desse cenário, os alunos perceberam que a reciclagem do lixo orgânico atua positivamente na preservação do meio ambiente, uma vez que a comunidade é favorecida em sua totalidade, permitindo a otimização dos serviços de saneamento, aumentando a vida útil dos aterros sanitários e produzindo um produto eficaz na fertilização de hortaliças e jardins, contribuindo nos aspectos financeiros e para a saúde dos indivíduos.

Após as atividades de fixação sobre os componentes presentes na reutilização do material orgânico, iniciou-se a construção da composteira escolar, quando foi colocado efetivamente em prática todo o aprendizado. Posteriormente, o composto proveniente da compostagem foi utilizado nas hortas e jardins das instituições, colaborando para o ciclo biogeoquímico com retenção dos nutrientes, para o reaproveitamento no local do consumo. Os professores foram capacitados para dar continuidade aos procedimentos da compostagem, permitindo a consolidação e o fortalecimento da prática da EA nas escolas. 
A última parte do projeto, onde houve a criação de redações e desenhos sobre o tema, levou a um resultado muito favorável. Foi possível observar a crescente participação e percepção dos alunos, através de construção de perguntas e de relatos de experiências vividas em casa. O comprometimento das crianças em se tornarem multiplicadoras de ações ambientalmente sustentáveis também foi notado.

\section{Discussão}

Com base na Política Nacional de Educação Ambiental, Lei nº 9.795/1999, a Educação Ambiental (EA) é um elemento necessário e permanente, devendo ser oferecida em todos os níveis e modalidades do processo educativo, de forma transversal e em caráter multidisciplinar (Brasil, 1999). A Educação Ambiental contribui para o processo de formação social do indivíduo, levando compreensão aos alunos acerca da responsabilidade sobre a interação do ser humano com o meio ambiente. Busca também enfatizar o respeito e a harmonia com a natureza, criando assim um novo modelo de comportamento sustentável. Segundo Medeiros et al. (2011), durante o processo de aprendizado, os alunos passam a ter uma nova percepção do meio ambiente e se tornam promotores transformadores relacionados à proteção ambiental.

$\mathrm{O}$ projeto ambiental teve como premissa principal levar à consciência das crianças do Ensino Fundamental I os benefícios decorrentes da compostagem, portanto, em razão do pouco conhecimento notado, ao levantar perguntas a respeito da compostagem, coleta seletiva e os impactos ambientais, é válido destacar que a extensão da pesquisa contribuiu significativamente no compartilhamento de informações e no desenvolvimento da sustentabilidade. Essa prática educativa integrada tem o importante papel na construção de valores coletivos que visem conhecimentos, habilidades, atitudes e competências apoiadas na concepção da conservação ambiental (Tavares, Sousa \& Santos, 2018).

As dinâmicas realizadas foram fundamentais para esclarecer e ressaltar a importância da colaboração coletiva em prol da natureza e de uma vida mais sustentável. O envolvimento dos alunos nesse processo capacita o pensamento reflexivo e crítico no ambiente atual, estimulando-os a uma participação ativa e com dispersão do conhecimento sobre as questões ambientais (Santos \& Fehr, 2007). Ademais, transmitir novas informações de forma lúdica e interativa, permite aos alunos induzir a liberdade do corpo e do pensamento dentro do ambiente escolar (Probst \& Kraemer, 2012), proporcionando a assimilação do conhecimento por meio da expressão coletiva e de ideias, bem como a oportunidade de evoluírem e se fazerem pessoas conscientes e de consumos sustentáveis.

Os resultados obtidos revelaram que as atividades em grupo incentivaram tais mudanças no comportamento, além da manifestação de apoio na formação de mecanismos da gestão de resíduos orgânicos, como a compostagem, e na multiplicação dos novos saberes. É através das crianças que se conscientiza a sociedade, uma vez que, elas transmitem os conhecimentos aos familiares, amigos e vizinhança, o que possibilita alcançar o desenvolvimento sustentável (Mothé et al., 2020).

A averiguação da compreensão ambiental por meio dos desenhos e textos das crianças permite a observação sob duas perspectivas, segundo Santos et al. (2017): uma percepção romântica e uma percepção de dominação, uma vez que, uma parcela das crianças ilustrou o meio ambiente indicando uma natureza bela e intocada pelo homem, enquanto outra parcela desenhou os elementos construídos pelo homem, em sua maior parte, quando comparados aos elementos naturais.

A Educação Ambiental nas escolas ajuda a formar cidadãos conscientes, que possam tomar decisões sob seu compromisso com a vida e o bem-estar social (Medeiros et al., 2011). A receptividade dos envolvidos no contexto escolar, desde os discentes e professores, até funcionários administrativos e cantineiras, levou a uma conscientização geral, impactando na rotina da instituição, onde os responsáveis pela refeição escolar passaram também a descartar adequadamente os restos de alimentos, contribuindo para a compostagem.

Em se tratando do objetivo central do projeto, pode-se concluir que estes foram alcançados de forma satisfatória, considerando o tempo curto de execução em cada escola, o baixo custo e o aprendizado permanente levado às crianças. 
Propõem-se que as escolas deem continuidade a esse e a novos projetos de EA, dentro e fora da sala de aula, e ampliem o conhecimento para as demais faixas etárias em caráter interdisciplinar. Métodos educacionais que lidam com os alunos de forma a colocá-los como atores sociais e protagonistas de trabalhos ambientais precisam ser desenvolvidas, pois a didática escolar não tem apenas o dever de repassar conteúdos, mas instruir por meio de ações e exemplos, as maneiras de assegurar a formação de cidadãos responsáveis acerca das questões ambientais (Silva \& Saraiva, 2020).

\section{Considerações Finais}

O processo educacional como forma de conhecimento se divide em formal e informal. O primeiro tem um caráter sistemático e direcionado, nomeadamente tratando da educação proporcionada pelo ambiente escolar, enquanto o segundo envolve a aprendizagem com a família (Gohn, 2006). Aprender é um processo no qual as crianças usam ativamente seu conteúdo por meio da experiência proporcionada por seu ambiente social. O conhecimento coletivo tende a ter maior valor e, portanto, há um maior compartilhamento de ideias.

O projeto "Brincando de compostar e aprendendo a reciclar" auxiliou positivamente no que diz respeito aos conhecimentos adquiridos pelos alunos e professores, através de atividades lúdicas, simples e objetivas, devidamente adequada ao público-alvo.

Diante dos resultados do projeto, é possível afirmar que a Educação Ambiental é um poderoso instrumento para a conscientização sobre os problemas socioambientais. Através dela, é possível a reconstrução dos conceitos, favorecendo a formação da consciência ambiental, por meio de novas atitudes sociais sustentáveis.

Por fim, recomenda-se para futuros estudos a análise da percepção da comunidade sobre o uso da compostagem doméstica, além do ensinamento de técnicas sobre o assunto, com aplicação em uma horta comunitária, incorporando o ciclo compostagem-colheita. Sugere-se também o monitoramento de composteiras escolares, bem como estudos de maneiras de aprimorar os conhecimentos dos alunos sobre o meio ambiente, desenvolvendo a sensibilização ambiental, especialmente em relação à gestão de resíduos sólidos.

\section{Agradecimentos}

Agradecemos aos docentes, discentes e demais funcionários das instituições de ensino envolvidos na execução deste projeto. Ao Programa de Apoio a Projetos de Extensão da UEMG- PAEx/ UEMG, pelo apoio financeiro concedido para o desenvolvimento do estudo. À Prefeitura Municipal de João Monlevade, pelo incentivo e colaboração durante o desenvolvimento desse trabalho.

\section{Referências}

Boff, L. (2012). Sustentabilidade: o que é, o que não é. Editora Vozes.

Brasil. Lei n. 9.795, de 27 de abril de 1999. Política Nacional de Educação Ambiental. Diário Oficial da União, Brasília, DF, 27 de abril 1999. http://www.planalto.gov.br/ccivil_03/leis/L9795.htm>

Brasil. Lei n. 12.305, de 2 de agosto de 2010. Política Nacional de Resíduos Sólidos. Altera a Lei nº 9.605 , de 12 de fevereiro de 1998 ; e dá outras providências. Diário Oficial da União, Brasília: Câmara dos Deputados, n. 81, $2010 \mathrm{~b}$.

Conto, S. D. de, Binz, P., Fabrim, C. F. \& Prates, M. P. (2018). Gastronomia sustentável e minimização de desperdícios/impactos ambientais. In Desperdício de alimentos: velhos hábitos, novos desafio (312-328).

Costa, A. R. S, Ximenes, T. C. F., Ximenes, A. F. \& Beltrame, L. T. C. (2015). O processo da compostagem e seu potencial na reciclagem de resíduos orgânicos. Revista Geama. 1(2), 116-130. http://www.journals.ufrpe.br/index.php/geama/article/view/503

Freeman, H. R. (2021). O princípio da equidade intergeracional na logística reversa dos resíduos sólidos. In Direito Ambiental e Resíduos Sólidos: perspectiva (inter)nacional transdisciplinar dos 17 ODS da ONU (53-64). Navida Editora.

Gil, A. C. (2012). Métodos e Técnicas de Pesquisa Social. (6a ed.), Atlas. 
Gohn, M. da G. (2006). Educação não-formal, participação da sociedade civil e estruturas colegiadas nas escolas. Ensaio: Avaliação e Políticas Públicas em Educação, 14(50), 27-38. https://doi.org/10.1590/S0104-40362006000100003

Google. Google Earth Pro. https://www.google.com.br/earth/download/gep/agree.html

Instituto brasileiro de geografia e estatística $(I B G E)$. https://www.ibge.gov.br/cidades-e-estados/mg/joao-monlevade.html

Ludke, M. \& André, M. E. D. A. (2013). Pesquisa em educação: uma abordagem qualitativa (2a ed). EPU.

Medeiros, A. B., Mendonça, M. J. S. L., Sousa, G. L. \& Oliveira, I. P. A. (2011). Importância da educação ambiental na escola nas séries iniciais. Revista Faculdade Montes Belos, 4(1), 1-17. http://revista.fmb.edu.br/index.php/fmb/article/view/30

Medrado, D. A. (2010). Estudo dos prejuízos ambientais e sociais, causados pela ausência do gerenciamento dos resíduos sólidos dos serviços de saúde do município de Santa Helena de Minas- MG. Monografia de especialização, Universidade Federal de Minas Gerais, Santa Helena de Minas, MG. https://www.nescon.medicina.ufmg.br/biblioteca/registro/referencia/0000007212

Mothé, G. P. B., Souza, G. R. de, Abreu, M. M. de, Gama, J. L., Mota, G. P., Almeida, T. F., Delatorre, A. B. \& Intorne, A. C. (2020). Compostagem e a educação ambiental: uma ferramenta importante no tratamento de resíduo sólido. Braz. J. of Develop., 6(7), 49520-49532, https://doi.org/10.34117/bjdv6n7557

Ministério do meio ambiente - MMA (2012). Plano Nacional de Resíduos Sólidos. https://sinir.gov.br/images/sinir/Arquivos_diversos_do_por tal/PNRS_Revisao_Decreto_280812.pdf>

Ministério do meio ambiente - (2020). Coleta Seletiva. http:/www.mma.gov.br/cidades-sustentaveis/residuos-solidos/catadores-de1materiaisrecicl aveis/reciclagem-e-reaproveitamento

Oliveira, L. S. B. L., Oliveira, D. S. B. L., Bezerra, B. S., Pereira, B. S. \& Battistelle, R. A. G. (2017). Environmental analysis of organic waste treatment focusing on composting scenarios. Journal of Cleaner Production, 155, 229-237.

Pitt, H. (2014). Therapeutic experiences of community gardens: putting flow in its place. Health \& Place, 27, 84-91. https://doi.org/10.1016/j.jclepro.2016.08.093

Probst, M. \& Kraemer, C. (2012). Sentado e quieto: o lugar do corpo na escola. Atos de pesquisa em educação (FURB), 7(2), 507-519. http://dx.doi.org/10.7867/1809-0354.2012v7n2p507-519

Santos, H. M. N., \& Fehr, M. (2007). Educação ambiental por meio da compostagem dos resíduos sólidos orgânicos em escolas públicas de Araguari. Caminhos de Geografia, 8(24), 163-183. http://www.seer.ufu.br/index.php/caminhosdegeografia/article/view/15719

Santos, F. A. S., Eckert, N. O. S., Oliveira, R. S., Silva Neto, H. G. da, Teixeira, L. N. \& Coelho, A. S. (2017). Percepção ambiental e análise de desenhos: prática em curso de extensão universitária. Revista Brasileira de Educação Ambiental, 12(2), 156-177. https://doi.org/10.34024/revbea.2017.v12.2358

Silva, J. S. da, \& Saraiva, E. de S. (2020). A importância da Sequência Didática (SD) na Educação Ambiental: um relato de experiência no Centro de Educação em Tempo Integral Monsenhor Boson. Research, Society and Development, 9(6), e156963505. https://doi.org/10.33448/rsd-v9i6.3505

Tavares, F. B. R., Sousa, F. C. de F. \& Santos, V. E. da S. (2018). A educação ambiental com perspectiva transdisciplinar no contexto da legislação brasileira. Research, Society and Development, 7(12), 01-22. https://doi.org/10.33448/rsd-v7i12.478

Teixeira, L. B., Germano, V. L. C., Oliveira, R. F. de \& Furlan Júnior, J. (2004). Processo de compostagem, a partir de lixo orgânico urbano, em leira estática com ventilação natural. Circular Técnica 33, Embrapa, Belém. https://ainfo.cnptia.embrapa.br/digital/bitstream/item/28113/1/Circ.tec.33.pdf>

Zhao, Y., Zhao, Y., Zhang, Z., Wei, Y., Wang, H., Lu, Q., Li, Y. \& Wei, Z. (2017). Effect of thermo-tolerant actinomycetes inoculation on cellulose degradation and the formation of humic substances during composting. Waste Management, 68, 64-73. https://doi.org/10.1016/j.wasman.2017.06.022 